\title{
Allergic Haematuria
}

\author{
P. AMMANN and E. ROSSI \\ From the University of Berne Paediatric Clinic, Berne, Switzerland
}

Allergic reactions are only rarely taken into consideration in the differential diagnosis of urological disorders (Campbell, 1951; Dees and Simmons, 1951). Histologically speaking, however, allergic reactions are just as capable of occurring in the urinary tract as they are in the respiratory or digestive tracts. Thus mast cells and histamine are to be found everywhere in the normal bladder wall (Simmons, 1961). The far greater incidence of allergies of the respiratory passages and, less commonly, of the intestine is no doubt due to the fact that these organs are directly exposed to all possible kinds of allergens, whereas the urinary passages are protected by the body coverings, by the metabolism, and by humoral antibodies.

Since Duke (1922) published his findings regarding bladder pains of allergic origin only occasional reports of similar symptoms have appeared. In a general review of the subject, Powell (1961) gives a list of symptoms that might be caused by an allergic reaction of the urinary passages. The symptoms given range from tenesmus and dysuria via haematuria to suprapubic pains and pains in the side. Cystoscopy in such cases frequently reveals a pale, oedematous mucosa with hyperaemic zones. Allergens mentioned include inhalants, drugs, foods, and causative organisms of infections. In the case of food allergy, symptoms of urinary tract reaction were observed 1 to 12 hours after ingestion of the food. Powell makes the interesting observation that allergic bladder and prostate disorders occur with greater frequency during holiday periods, i.e. when unaccustomed foods are on the table. Citrus fruits head the list of allergenic substances, followed by tomatoes, spices, chocolate, and nuts. More recently interstitial cystitis, in particular, has been assigned an allergic origin, and an account has been given of successful treatment with antihistamines (Simmons, 1961).

Besides haematuria in Henoch-Schönlein purpura, which is almost certainly of allergic origin, and other allergic glomerular lesions, there is also an isolated form of allergic haematuria, which is

Received February 10, 1966. frequently in fact dismissed as 'essential haematuria'. The few cases that we have been able to find reported (Adelsberger, 1931; Coca, 1930; Eisenstaedt, 1949; Kittredge and Johnson, 1949; Miller and Uhle, 1939; Rhodes, 1937; Thomas and Wicksten, 1944) can now be supplemented by a further case, treated by ourselves, that presents a number of points of interest.

\section{Case Report}

History. The patient was a 3-year-old boy. His mother's family were victims of eczema, asthma, and hay fever. At the age of 4 weeks the patient developed seborrhoeic dermatitis, which later changed into obstinate eczema. At 5 months asthma-bronchitis appeared for the first time, and subsequently the patient suffered repeatedly from genuine asthmatic attacks, for which his family physician prescribed steroid therapy lasting for several months. From the age of $2 \frac{1}{2}$ onwards episodes of haematuria lasting 1 to 2 days were repeatedly observed; the patient, however, felt no pain. At the age of 3 the boy was admitted to this Paediatric Clinic for investigation.

Clinical examination. This revealed nothing abnormal apart from retarded growth (height below the 3rd centile, weight on the 3 rd centile). Blood findings: $\mathrm{Hb} 13.5 \mathrm{~g} . / 100 \mathrm{ml}$., leucocytes 6,700 with no shift to the left, $6 \%$ eosinophils; bleeding time 2 minutes, coagulation time 4 minutes 30 seconds, prothrombin time $95 \%$, thrombocytes 300,000 ; blood pressure $100 / 60 \mathrm{~mm}$. Hg; tuberculin test negative; serum electrolytes, protein, cholesterol, bilirubin, urea $\mathrm{N}$, alkaline phosphatase, cholinesterase, and transaminases all normal. Urine: sediment negative, no protein, calcium not increased, benzidine test negative, bacteriological examination negative; creatinine clearance $168 \mathrm{ml} . / \mathrm{min} .1 .73 \mathrm{~m}^{2}$; concentration test up to 1030 , dilution test up to 1001 ; aminoaciduria normal. Radiography of abdomen and intravenous pyelography gave normal pictures with no indication of urinary calculi. Cystoscopy revealed minor lesions in the mucosa of the bladder without inflammatory changes. No foreign bodies, tumours, or angiomas. Chromocystoscopy normal for both ureters.

Comment. On the basis of the history, clinical examination, and laboratory findings, it was possible to rule out the following as being responsible for the haematuria : haemorrhagic diathesis, kidney disease, 
congenital haematuria, nephrolithiasis, and inflammatory, neoplastic, or angiomatous changes in the urinary passages.

The mother was questioned further regarding the haematuria, and it then transpired that it took place only on Sundays. Every Sunday pineapples were served at table, this being the only difference in the family's eating habits with respect to weekdays. By way of provocation test, therefore, we gave the child some canned pineapple. Approximately 4 hours later a severe asthmatic attack occurred, accompanied by vomiting. During the attack the eosinophilia figure was $6 \cdot 5 \%$. No haematuria occurred. The following day the eosinophils had dropped to $0.5 \%$.

In order to allow for any possible denaturation of the preserved fruit, the child was 5 days later given fresh pineapple. One hour later another severe attack of asthma occurred, accompanied by vomiting, and shortly afterwards massive haematuria that lasted for $1 \frac{1}{2}$ days. Apart from erythrocytes in great numbers no pathological findings were obtained from the urine, and in particular no protein or concretions. No eosinophils could be found in the sediment, but the eosinophils in the blood again rose to $10 \%$. Two days later an eczematous rash appeared on both hands.

When a period of 8 months had passed during which the patient received no pineapple and remained free from haematuria, a further provocation test was carried out. Before the test the eosinophils in the blood were $3 \%$, and the urine findings ware normal. Four hours after the ingestion of fresh pineapple marked erythrocyturia again occurred, the urine otherwise remaining normal. In the blood the eosinophils rose to $12 \cdot 5 \%$. No asthmatic attack took place on this occassion.

The skin test (scratch test with Bencard allergens) showed no reaction to fruits or other foods, but gave definite positive results with various inhalation allergens.

The repeated success of the provocation test using pineapple, the simultaneous appearance of haematuria, asthma, and eosinophilia, and the delayed eczematous reaction adequately demonstrated the allergic nature of the haemorrhage in this case.

It was unfortunately not possible to determine whereabouts in the urinary tract the haemorrhage occurred. A three-glass test could not be carried out in view of the youth of the patient. The absence of protein and erythrocyte casts would make a glomerular origin unlikely (Allen, Diamond, and Howell, 1960; Bergstrand, Bergstrand, and Bucht, 1960). Possible sources were the renal pelvis and the infrarenal urinary passages.

In 11 earlier cases of allergic haematuria (Adelsberger, 1931; Coca, 1930; Eisenstaedt, 1949; Kittredge and Johnson, 1949; Miller and Uhle, 1939, Rhodes, 1937; Thomas and Wicksten, 1944) the allergens were identified as foods in 7, drugs in 2 , and inhalants and solar radiation in 1 each. Cystoscopy was carried out in 4 cases, and revealed bleeding from one or both ureters. Powell (1961), on the other hand, regards allergic haematuria as a lower tract symptom (bladder, prostate, and urethra).

It should again be stressed in this connexion that skin tests for food allergies are not reliable (Unger, Kubik, and Unger, 1959). Only provocation and elimination tests make diagnosis possible in such cases.

Because of their rarity, urological disorders of allergic origin all too often fail to be recognized. The case just described, however, shows that, especially where the cause of haematuria is not clear, attention should be paid to the possibility of an allergic reaction before the diagnosis "essential haematuria' is made.

\section{Summary}

Allergic reactions in the urinary tract are rare. Probably most allergens are intercepted before they can penetrate this far into the body. The most common allergens are foods. An account is given of one case of allergic haematuria caused by eating pineapple. The diagnosis was confirmed by repeated application of the provocation test: haematuria was accompanied by asthma and eosinophilia and on one occasion was followed by an eczematoid rash. The site of the haemorrhage could not be determined but could with reasonable certainty be assumed to be infrarenal. Eleven similar cases were found in the literature.

\section{REFERENCES}

Adelsberger, L. (1931). Zum Symptomenbild und zum Krankheitsverlauf der allergischen Krankeiten. Dtsch. med. Wschr., 57, 585.

Allen, D. M., Diamond, L. K., and Howell, D. A. (1960). Anaphylactoid purpura in children (Schönlein-Henoch syndrome). Amer. F. Dis. Child., 99, 833.

Bergstrand, A., Bergstrand, C. G., and Bucht, H. (1960). Kidney lesions associated with anaphylactoid purpura in children. Acta paediat. (Uppsala), 49, 57.

Campbell, M. F. (1951). Clinical Pediatric Urology. W. B. Saunders, Philadelphia and London.

Coca, A. F. (1930). Specific sensitiveness as a cause of symptoms in disease: essential hematuria and localized retinal edema as possibly allergic symptoms. Bull N.Z. Acad. Med., 6, 593.

Dees, S. C., and Simmons, E. C. (1951). Allergy of the urinary tract. Ann. Allergy, 9, 714.

Duke, W. W. (1922). Food allergy as a cause of bladder pain. Ann. clin. Med., 1, 117.

Eisenstaedt, J. S. (1949). Allergy of the pelvic urinary tract in the female. (Discussion.) f. Urol. (Baltimore), 61, 230.

Kittredge, W. E., and Johnson, C. (1949). Allergic hematuria due to milk. New Orleans med. surg., $\mathcal{F} .101,419$.

Miller, M. W., and Uhle, C. A. W. (1939). A survey of urinary tract allergy. Int. Clin., 3, 183.

Powell, N. B. (1961). Allergies of the genito-urinary tract. Ann. Allergy, 19, 1019.

Rhodes, J. (1937). Hematuria after the use of a tetanus antitoxin. Report of a case. $\mathcal{F}$. Urol. (Baltimore), 38, 410.

Simmons, J. L. (1961). Interstitial cystitis: an explanation for the beneficial effect of an antihistamine. ibid., 85, 149.

Thomas, J. W., and Wicksten, V. P. (1944). Allergy in relation to the genito-urinary tract. Ann. Allergy, 2, 396.

Unger, D. L., Kubik, F., and Unger, L. (1959). Urinary tract allergy. F. Amer. med. Ass., 170, 1308. 